\title{
Innovative Activity as a Factor of Anti-Crisis Development in the Conditions of State Support (On The Example of Naberezhnye Chelny)
}

\author{
${ }^{1}$ Ekaterina V. Krotkova, ${ }^{2}$ Aminova R. Mullamekhametovna \\ ${ }^{1,2}$ Kazan Federal University, Republic of Tatarstan, Naberezhnye Chelny, 68/19 (1/18), 335, 423810
}

Email:nek_m@rambler.ru, Contact: +79600705088

Received: 15th December 2017, Accepted: 20th December 2017, Published: 31st December 2017

\begin{abstract}
This paper deals with the features of innovative development within the framework of anti-crisis management. The problem of managing organizations in crisis conditions is most relevant today, while effective anti-crisis management should bring the organization to a new level of development. Innovations are relevant with timely anti-crisis management, a shortage of resources allows using effectively state support and conditions that make it possible to implement changes. The methodological basis of the study is a dialectical method of cognition and a systematic approach to the analysis of the studied facts and phenomena. Methods of analysis used in various combinations at each stage of the study, depending on the purpose of the study and the problems examined, contributed to the increase of the reliability and validity of the conclusions made by the author. The results of implementation of the programs of state support of small business in the Republic of Tatarstan of the Russian Federation, in particular in the city of Naberezhnye Chelny, are analyzed. Based on the analysis, the main problems arising in the implementation of state programs are outlined. It is emphasized that the implementation of state support programs for small and medium-sized businesses is an important factor in the innovative development of enterprises and the overall economy of the region. Such a conclusion allowed for a comparative analysis of two innovative sites of the Krai Innovative Platforms "Master" and Business Incubator in Naberezhnye Chelny. The paper substantiates the necessity of the subsequent monitoring of enterprises that have received state support.
\end{abstract}

Keywords: Innovation, Crisis Management, Efficiency, State Support, Entrepreneurship, Innovative Platforms

\section{Introduction}

Anti-crisis management occupies an increasingly important niche in management theory and practice, as the problem of effective management in a multifactor dynamic environment and uncertainty that contributes to crisis phenomena grows worse. The problem of managing organizations in crisis conditions is relevant for today's Russia, and management faces the challenge of ensuring the sustainable functioning and development of organizations in the long term under recurring crises

$$
\text { [1]. }
$$

Some sources see the crisis as "... an extreme aggravation of intra-production and socio-economic relations in the internal environment of the organization, as well as relations with the external environment; state of destruction of the existing system of parameters of its activities" [2].

Accordingly, an effective anti-crisis management should bring the organization to a new level of development. According to Zakharov V. Ia., the main function of the crisis is the destruction of the least stable and viable elements [3].

In the economy, the crisis destroys many of the weakest and least expediently organized enterprises, eliminating obsolete methods of production, forms of organizing enterprises in favor of more modern ways and forms. Schumpeter spoke of "creative destruction", understanding it as "the process of industrial mutation, which continuously reconstructs the economic structure from within, destroying the old and creating new one" [4]. According to the results of the research conducted by Cornell University (USA), INSEAD Business School (France) and the World Intellectual Property Organization in 2016, Russia ranks 43rd among 128 countries, having improved its position by five points as compared to the previous year [5]. At the same time, researchers at the Higher School of Economics, Gokhberg, Rud, point out that the effectiveness of innovation activity of the country is significantly weaker, which reflects a lack of effective implementation of the available innovative potential [6].

According to V.I. Orekhov and K.V. Baldin, in the modern market, a system that underestimates the role of innovation potential weakens its positions in the markets, loses consumers and reduces profit margins. All this contributes to the emergence of a crisis situation [7, P.170-171].

Innovations are aimed at both the internal environment of the organization and the external one. At the same time, innovative activity in crisis management is risky. This, in our opinion, is due to two contradictory trends. On the one hand, innovation destroys stability and sustainability, forcing socio-economic systems to change, and on the other, they are called upon to bring systems to a 
new qualitative level and ensure stable development. At the same time, it is necessary to know at what stage of the crisis the innovations are a necessary condition for crisis management, and at which of them they are ineffective. This depends, first of all, on the availability of resources [8]. As we know, the crisis situation is characterized by a shortage of cash, an outflow of highly professional personnel, a limited time, which is a prerequisite for the implementation of the innovation strategy. Accordingly, innovations are most appropriate for early crisis management; resource scarcity [9, pp. 1215] instigates to an effective of a state support and conditions that enable the implementation of changes aimed at introducing innovations. The earlier this need is realized by managers, the more effective the preventive activity will be [3, P.26].

\section{Methods}

The Republic of Tatarstan has adopted a number of Programs [10] aimed at supporting, stimulating and developing small and medium-sized businesses. Targeted and effective use of allocated funds, as well as implementation of activities under approved programs, is controlled by the Accounts Chamber of the Republic of Tatarstan.

The asymmetry indicator of small business development was analyzed [11]. The efficiency of enterprises is determined by means of the following indicators: the scope of the variation in labor productivity, the asymmetry of labor productivity, and the asymmetry of tax returns. The indicators will allow determining the changes in the studied set of values, deviation from the mean value and the change in the asymmetry of the performance results by a comparative analysis of enterprises that are residents of the KIP "Master" of the city of Naberezhnye Chelny and enterprises operating in similar sectors of the regional economy without the support of these platforms.

We conducted the analysis of the dynamics of the indicators for the last three years, which allowed us to draw conclusions on the change in the entirety of the residents of the KIP "Master" and "Business Incubator" of Naberezhnye Chelny, as well as a comparative analysis in order to implement innovations and use the conditions for their implementation.

\section{Results and Discussion}

Analysis of the dynamics of the activities of Business Incubator of Naberezhnye Chelny, presented in Fig. 1 shows that residents are more involved in the field of information and communication, and this dynamic is stable. In 2016, such activities as the production of finished metal products, other than machinery and equipment and the production of other vehicles and equipment, came from the business incubator. In turn, the proportion of residents engaged in the production of other non-metallic mineral products, food production, transportation and storage, has increased significantly.

It is also worth noting the appearance in 2016 of a resident who carries out activities directly in the field of research and development.
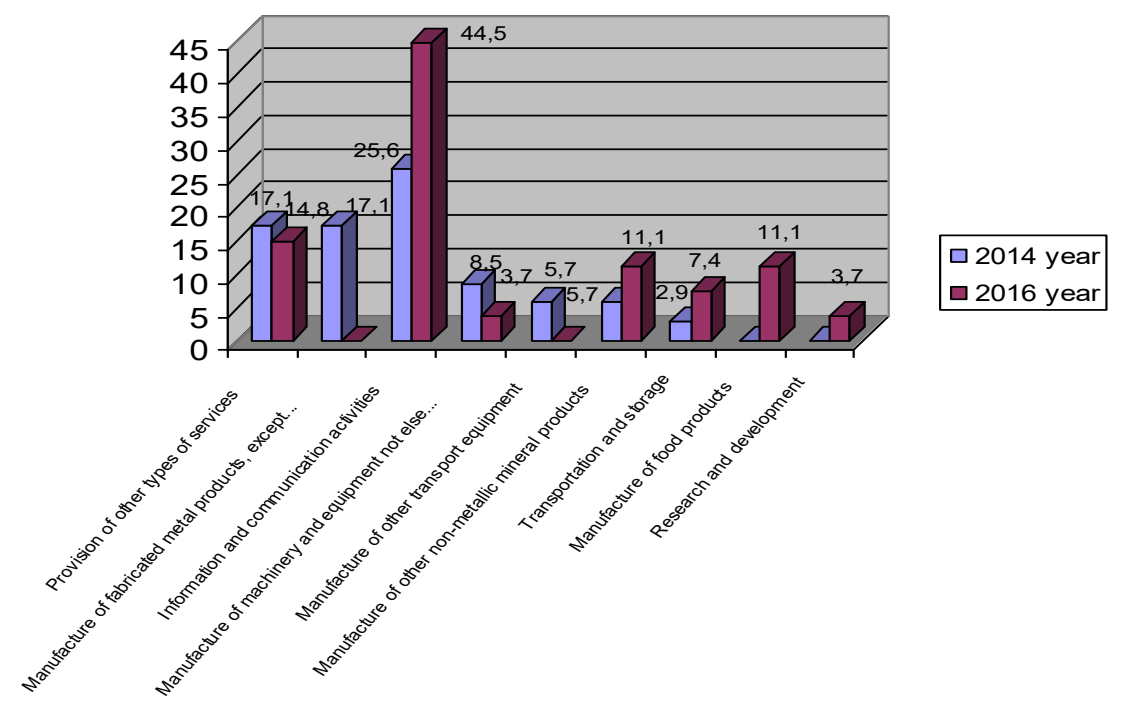

Fig. 1. Types of Economic Activity of Business-Incubator, Naberezhnye Chelny

The KIP "Master" has slightly different situation, since this platform implements other goals, while residents have similar preferences as in Business
Incubator. The largest share is made by residents engaged in trading activities $(21.7 \%)$ and production of other vehicles and equipment $(20.9 \%)$. 


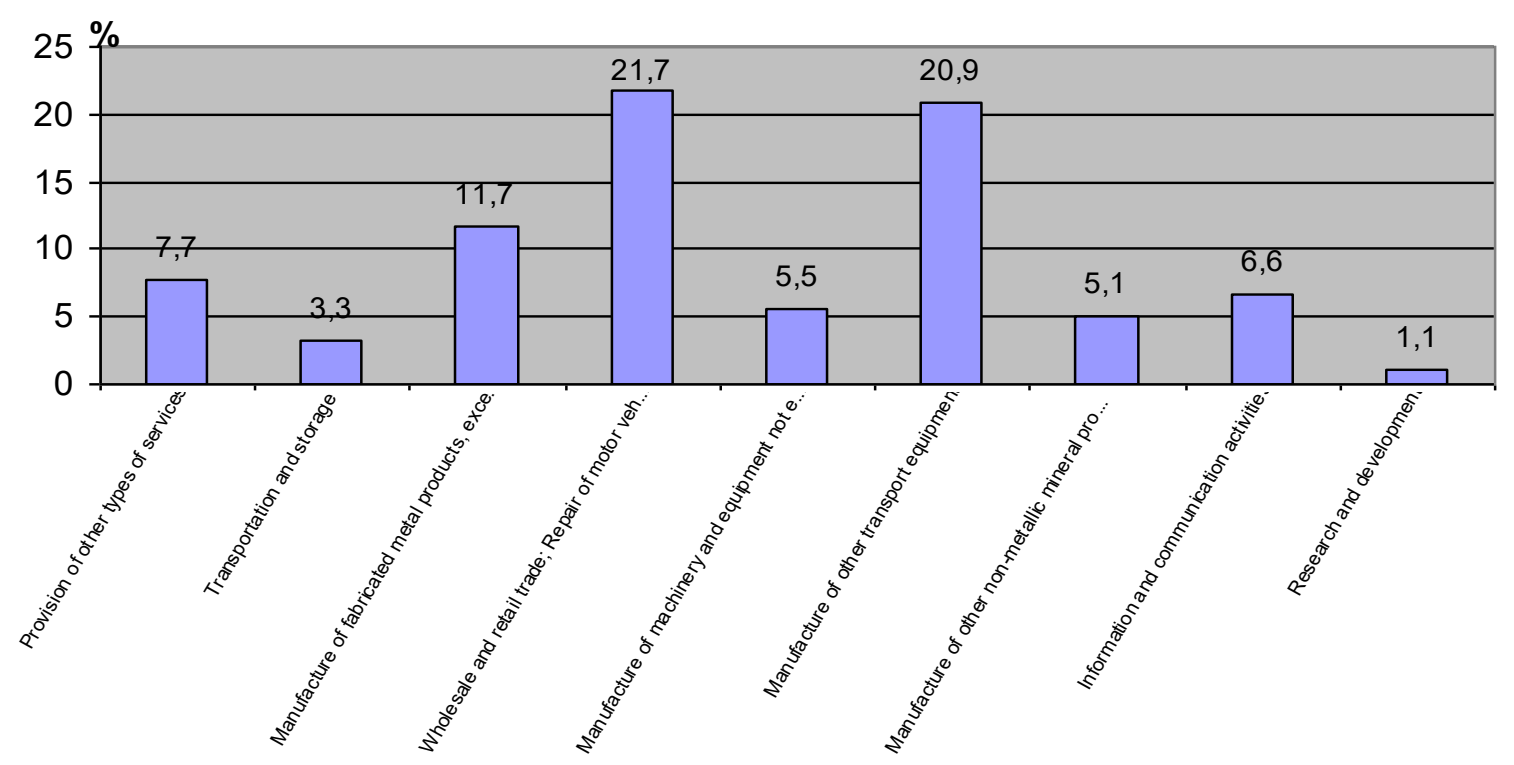

Fig. 2. Types of Economic Activity of KIP "Master", Naberezhnye Chelny, 2016

A comparative analysis of the activities of the KIP "Master" and Business Incubator in Naberezhnye Chelny showed the following: Business Incubator pursues the goal of increasing innovation among its residents, with only one resident announcing scientific research and development, and the KIP "Master" is represented by three residents.

The considered method of assessing the asymmetry of the development of small business was tested using the KIP "Master", Naberezhnye Chelny, as an example. As a source of data for the calculation of labor productivity, statistical indicators of the activity of small businesses in the context of the municipality (Naberezhnye Chelny) for 2013-2016 were used.

In the course of the analysis it was found out that not only the average labor productivity in each industry fluctuates, but also its individual values for each enterprise, included in the studied aggregate (Table $1)$.

Table 1 - Range of variation in the labor productivity of residents and non-residents of the
KIP "Master", Naberezhnye Chelny, thousand rubles".

As can be seen from the calculations, the scope of labor productivity variation for companies operating in the production of vehicles and equipment, both residents and non-residents, is more "stable". The labor productivity growth reserves are available to all; in case of achieving maximum labor productivity, the average production volume will be higher for non-residents of the KIP "Master" than for residents.

A similar situation is observed in enterprises operating in the production of finished metal products, except machinery and equipment. Residents, in turn, have a small scale of variation, in addition, their growth rates of labor productivity decline. Non-residents of the KIP "Master" will have a larger average value, in the case of maximum labor productivity, therefore, their growth reserves are higher than those of residents.

The range of variation does not catch the variability of the variants within the studied aggregate.

\footnotetext{
${ }^{1}$ Here and in other tables, the authors calculated indices on the basis of the data of the studied objects
} 
Table 2. - Asymmetry of the Labor Productivity of Residents and Non-Residents of the KIP "Master", Naberezhnye Chelny

\begin{tabular}{|l|c|c|c|c|c|c|c|c|}
\hline & \multicolumn{4}{|c|}{$\begin{array}{c}\text { Manufacture of other transport } \\
\text { equipment }\end{array}$} & \multicolumn{3}{c|}{$\begin{array}{c}\text { Manufacture of fabricated metal } \\
\text { products, except machinery and } \\
\text { equipment }\end{array}$} \\
\hline $\begin{array}{l}\text { Coefficient of } \\
\text { asymmetry }\end{array}$ & $2013 \mathrm{y}$ & $2014 \mathrm{y}$ & $2015 \mathrm{y}$ & $2016 \mathrm{y}$ & $2013 \mathrm{y}$ & $2014 \mathrm{y}$ & $2015 \mathrm{y}$ & $2016 \mathrm{y}$ \\
\hline Residents & $-0,891$ & 0,167 & 0,381 & 0,411 & $-0,789$ & 0,119 & 0,346 & 0,467 \\
\hline Non-residents & 0,382 & 0,491 & 0,501 & 0,671 & 0,234 & 0,378 & 0,502 & 0,498 \\
\hline
\end{tabular}

Table 2 shows that the asymmetry coefficients are mostly positive, therefore, enterprises have higher labor productivity indices. The indicator of nonresidents of the KIP "Master", working in both industries, is positive and increasing, which indicates the interest of enterprises in the growth of labor productivity. The situation is different for residents: until 2014, the indicator in question was negative, i.e. had a left-sided asymmetry, which indicates a decline in labor productivity and the prevalence of values below the average.

Table 3 - Asymmetry of Tax Return of Residents and Non-Residents of the KIP "Master", Naberezhnye Chelny

\begin{tabular}{|c|c|c|c|c|c|c|c|c|}
\hline & \multicolumn{4}{|c|}{$\begin{array}{c}\text { Manufacture of other transport } \\
\text { equipment }\end{array}$} & \multicolumn{4}{c|}{$\begin{array}{c}\text { Manufacture of fabricated metal } \\
\text { products, except machinery and } \\
\text { equipment }\end{array}$} \\
\hline $\begin{array}{l}\text { Coefficient of } \\
\text { asymmetry }\end{array}$ & 2013 y & 2014 y & 2015 y & 2016 y & 2013 y & 2014 y & 2015 y & 2016 y \\
\hline Residents & $-0,691$ & $-0,936$ & 0,367 & 0,389 & $-0,678$ & $-0,893$ & 0,210 & 0,391 \\
\hline Non-residents & $-0,921$ & 0,287 & 0,457 & 0,501 & $-0,892$ & 0,129 & 0,371 & 0,383 \\
\hline
\end{tabular}

The analysis of the asymmetry of tax returns showed that the tax return is higher for non-residents engaged in the production of other vehicles and equipment. If before 2014 the asymmetry indicator was negative, then in 2016 it showed a positive return to budgets of all levels. A similar situation is observed in non-residents engaged in the production of finished metal products, except machinery and equipment.

Enterprises-residents of the KIP "Master", operating in both industries, reached indicators above the average only during the last two years. Thus, the return from enterprises-non-residents is higher and more favorable for the development of the city and the region as a whole, under certain preferential working conditions. A similar situation was observed among enterprises operating in the studied sectors and being residents of Business Incubator of Naberezhnye Chelny [11].

When analyzing the activity of the two platforms, we took into account all residents, among which there is a small share of those not represented in Figures 1 and 2. Note in Business Incubator they include such activities as: the production of machinery and equipment not included in other groupings, furniture production, research and development $-3.7 \%$ each. The largest share $(44.5 \%)$ is occupied by residents engaged in information and communication activities. These are companies providing consulting services in the field of information technology. Unfortunately, organizations represented in the same field are less involved in research and development. In 2016, a new sphere of activity emerged - food production $11.1 \%$ of residents. Over the past three years, the number of residents engaged in industrial production has halved and amounted to $18.5 \%$ in 2016 . The platform lost such activities as: the production of finished metal products, except machinery and equipment, the production of other vehicles and equipment, the production of electrical equipment. At the same time, the number of companies in the sphere of transportation and storage increased almost 2.5 times. Since the KIP "Master" is designed for the accommodation of enterprises, primarily those operating in the machine-building industry, the manufacturing sector is represented by $51.97 \%$ of residents. 
The conducted research showed that granting preferential terms for business and innovation development is an important factor of innovative development, and effective use of these conditions is a contentious issue. As the researchers note, the Russian business environment is characterized by a low efficiency of state institutions [12]. Thus, according to the World Economic Forum, in 2015 Russia ranked 102nd in terms of the efficiency of state institutions, and 97th in terms of quality of its institutes out of 144 countries [13].

\section{Summary}

The Republic of Tatarstan has been implementing a number of state programs aimed at innovative development of both the enterprises themselves and the republic in general. The analysis of the KIP "Master" and Business Incubator has shown that the preference conditions are not effectively used to increase innovation activity. An insignificant share of residents is represented in the sphere of scientific research and development: KIP "Master" - 3 residents, Business Incubator - 1 resident.

There is a trend towards the growth of residents operating in the service sector. A significant share is occupied by the sphere of trade (intermediary services) with spare parts, car components, and the provision of consulting services. About $50 \%$ of residents (KIP "Master") carry out their activities aimed at meeting the needs of KAMAZ.

Calculation of the coefficient of labor productivity asymmetry showed higher values in non-resident companies of the platforms than in those enjoying preferential terms for doing business. A similar situation can be traced with the coefficient of asymmetry of tax returns. Non-resident companies generate more tax deductions than residents. Based on the conducted research, it can be determined that non-resident enterprises are more focused on making profits, improving their competitive advantages, optimizing production, and increasing labor productivity; in addition, their tax return is higher. The same cannot be said of residents: having preferential working conditions, they are on par with enterprises that operate independently, while the return of their financial investments is lower. At the same time, according to statistical data, more than $50 \%$ of enterprises are liquidated, after the termination of getting preferences in work (for example, exit from Business Incubator). The state providing preferential terms and support to business receives less return from the activities of residents in the form of tax deductions and the growth of labor productivity.

\section{Conclusion}

The main factor of crisis management is innovation, which is designed to bring the socio-economic system to a new level. At the same time, the introduction and development of innovations require certain investments that have a long-term effect, but in the short term are associated with increased costs, which in turn is a problem in times of crisis. One way to solve this problem is to provide state support to economic entities. Granting favorable conditions for doing business by the state in order to increase the efficiency of activities, as research has shown, is a lenient factor rather than stimulator of innovative development and increased efficiency. Thus, innovative development, which is a factor in anticrisis activities in the context of state support, is not effective enough and requires state control measures [14].

\section{Acknowledgements}

The work is performed according to the Russian Government Program of Competitive Growth of Kazan Federal University.

\section{References}

1. Anti-crisis management: College textbook / Ministry of Education and Science of the Russian Federation, State University of Management; Ed. E.M. Korotkov - 2nd ed., revised and corrected. M.: "Infra-M", 2009. - p. 620.

2. Kochetkova A.I. Fundamentals of management in chaos (uncertainty) / A.I. Kochetkova. - M.: Rid Grupp, 2012. - p. 624.

3. Aminova R.M. The importance and role of control in anti-crisis management. // Kazan economic bulletin. No.3 (11), 2014. - p.26.

4. Joseph A. Schumpeter. Capitalism, Socialism and Democracy, The Economic Journal 53. - 1943, - p.382

5. Innovation towards a knowledge-based economy. TenYear Plan for South Africa (20082018). Department of Science and Technology. - № 114538 - CapeTown, 2007. - 34 p.

6. Ltonid Gokhhberg and Vitaly Roud, How to Design a National Innovation System in a Time of Global Innovation Networks: A Russian Perspective, National Research University - Higher School of Economics. Electronic resource: http://www.wipo.int/edocs/pubdocs/en/wipo_pub_g ii_2016-chapter13.pdf

7. Orekhov V.I., Baldin K.V., Orekhova T.R. Anticrisis management: study guide. - 2nd ed., revised. M.: INFRA-M, 2013. - p. 267.

8. Ramstad E. Organizational view to innovation systems and policy in four European countries, in: Inken Gatermann, Myriam Fleck (Hg.): «Innovations fähigkeit sichert Zukunft. Beiträge zum Zukunft sforum Innovations fähigkeit des 
BMBF». - Berlin, Duncker \& Humblot, 2010. - p. 153-164.

9. Aminova R.M. Evolution of control in the management system // Economics and Entrepreneurship. 2017. No. 2-2 (79-2). p. 1215.

10. Development of small and medium-sized business in the Republic of Tatarstan for 2011-2013 (Decree of the Cabinet of Ministers of the Republic of Tatarstan No. 1151 of 30.12.2010), Youth Entrepreneurship in the Republic of Tatarstan for 2012-2016 (Decree of the Cabinet of Ministers of the Republic of Tatarstan No. 628 of 25.07.2012), etc.

11. Krotkova E. V., Mullakhmetov K. S., \& Akhmetshin E. M. (2016). State control over small business development: approaches to the organization and problems (experience of the Republic of Tatarstan, the Russian Federation). Academy of Strategic Management Journal, 15(1), 15-21.

12. Sadriev R. D., Mullakhmetov K. S., Krotkova E. V. \& Gabaidullina L. A. (2016). Introduction of Lean Production at Russian Enterprises: Perspectives and Problems. International Journal of Economics and Financial Issues. 6(S8), 39-48.

13. World Economic Forum. The Global Competitiveness Report 2014-2015. [Electronic resource]. - $\quad$ Access mode: http://www.weforum.org/reports/globalcompetitive ness-report-2014-2015

14. Mullakhmetov, K. S., Aminova, R. M., \& Akhmetshin, E. M. (2014). Control in a management system in modern conditions. Asian Social Science, 10(24), 237-247. http://dx.doi.org/10.5539/ass.v10n24p237 